\title{
Research on the Computer and 3D Modeling and Printing Technology with the Applications in Modern Civil Engineering
}

\author{
Qian cheng Fang \\ Huang Huai University, \\ Zhumadian 463000, China \\ fangqiancheng314@126.com

\section{Li Shang} \\ Huang Huai University, \\ Zhumadian 463000, China \\ Yong hui Shang \\ Huang Huai University, \\ Zhumadian 463000, China
}

\begin{abstract}
In this paper, we conduct research on the computer and 3D modeling technology with the applications on the modern civil engineering. Civil engineering is an important technology of the people to transform nature, the civil engineering in the actual construction technology for the human production and living provides a favorable safeguard and production needs, the human life has very important significance. After years of development and practice, in today's society, civil engineering has become a comprehensive discipline, with multiple branches, played an indispensable role in all aspects. And after years of development and technological innovation, civil engineering technology not only has improved, but also spawned many other technologies have great effect on the human production and living. Our research starts from the general analysis on the corresponding issues with the general applications that are innovative.
\end{abstract}

Keywords: 3D Modeling, Civil Engineering, Computer Techniques, Modern and Current.

\section{Introduction}

Civil engineering is one of engineering branches which are intimate relationships with architecture discipline. Civil engineering and engineering technology is a kind of production activity, including such as earth, stone, brick, engineering materials such as wood, concrete, plastics, and houses, roads, railways, bridges, tunnels, river, port, special structure and primary municipal health engineering construction as the abundance of gradually with the development of the theory, the civil engineering gradually to develop in the direction of specialization, such as the engineering materials, construction materials, etc. In our country, in the modernization construction of civil engineering is more and more become the pillar industry of national economy development. After years of development, the current civil engineering practice and research have made remarkable achievements, whether the structure of the mechanical analysis, or the structural design theory and method and structure of the construction method, has the very big breakthrough especially in recent years, at the top, big span structure and the steel structure performance is especially striking [1-2].

According to the literature review, the general challenges for the modern civil engineering could be generally summarized as follows. (1) Lack of acceptance standards and specifications. Some areas lack of construction control concepts and ways of thinking, more top at all. There are also some areas have general standards, but most of the creation of the first project is still lack of scientific research. For how to put forward the standard of the construction control, not only relates to the long-term development problem, also involves the operational problem. (2) Theory study also cannot adapt to the needs of the engineering construction, due to the general construction control involving multiple disciplines, especially in nonlinear analysis, feedback analysis, optimal control, 
system identification, analysis, etc., current research, the basic theories of both general and applied theory research, but there is lack of system integration and core application value. (3) The basic problem of management system. Responsibility is main problems existing in bull management, management can't implement, lack of attaches great importance to the construction control, the oversize project prophase research is insufficient, anatomy of the engineering are careful enough. To solve this problem, the only way is to realize the design and construction general contracting management thoughts, make the management responsibility clear and the implemented. Control emphasizes the construction unit should take the initiative that make the responsibility, right and capable of achieving the system unification [3-4].

The development of the computer technology also brings to the civil engineering the great leap forward, for the buildings, roads, railways, bridges, tunnels and other professional, the corresponding calculation software is developed for the civil engineering design brings a big breakthrough. With the speeding up of the informationization, the development of civil engineering information exchange got good progress, for various construction projects, and even the international project advantage theory, that can learn to communicate with their colleagues.

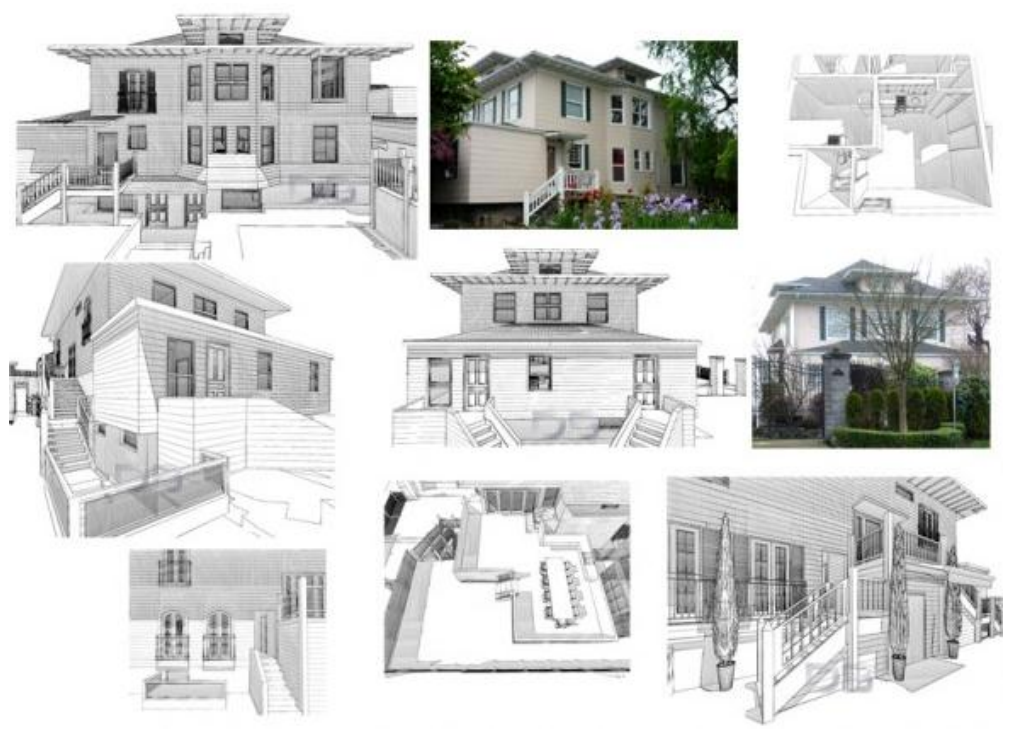

Figure 1. The Demonstration of the 3D Modeling Technology

In this paper, we conduct research on the computer and 3D modeling technology with applications on modern civil engineering. In civil engineering construction and natural struggle constantly move forward and development. Skyscrapers of the city, all kinds of bridges, water conservancy projects, roads extending in all directions throughout the various provinces and cities. Civil engineering is the guarantee of human living and traffic pillar industry, perfect the construction of civil engineering and development, realizing the unity of economic, social and environmental coordinated development, become the attention focus in the civil engineering. Human in order to strive for the survival, to win a comfortable living environment is expected to civil engineering will have a significant development.

\section{The Proposed Methodology}

The 3D Modeling and Printing. 3D printing is in the modern CAD technology, the mechanical engineering, layered manufacturing technology, laser technology, and the computer numerical control technology, precision servo drive technology and new materials technology developed on the basis of integration. Different kinds of rapid prototyping system because of the 
different forming materials used, the forming principle and system characteristics are different. However, they are the same, the basic principle of that is the "layered manufacturing, layered overlay", similar to the mathematical integral process. Figuratively speaking, rapid prototyping system is like a "3D printers", hence the name for the $3 \mathrm{D}$ printers. The application of 3D printing will profoundly change from the following three aspects for the traditional manufacturing [5].

- $3 \mathrm{D}$ printing has changed through the study of the production of raw materials for cutting and assembling the processing mode, save the material and the processing time. Application in the field of aerospace industry, for example, the metal parts are usually made of the high cost of solid titanium processing, $90 \%$ of the material is removed and the cutting material for aircraft manufacture is out of use value.

- 3D printing will be possible to change the second industrial revolution to produce the mass production methods, represented by assembly line, make products personalized, customized production. Application of 3D printers will shorten the time of the product to the market, consumers simply download the design drawing, within a few hours on a 3D printer can be product "print", which does not need to mass production line, don't need a lot of production workers, and don't need a lot of inventory parts namely the so-called social manufacturing.

- $3 \mathrm{D}$ printing is the primary integrated application of CAD/CAM technology, laser technology, photochemical, control, network, and materials science technology and knowledge of many aspects, such as high and new technology. Of 3D printing technology will promote the new material technology and intelligent manufacturing technology to realize the big leap, thereby giving impetus to the development of relevant industries [6].

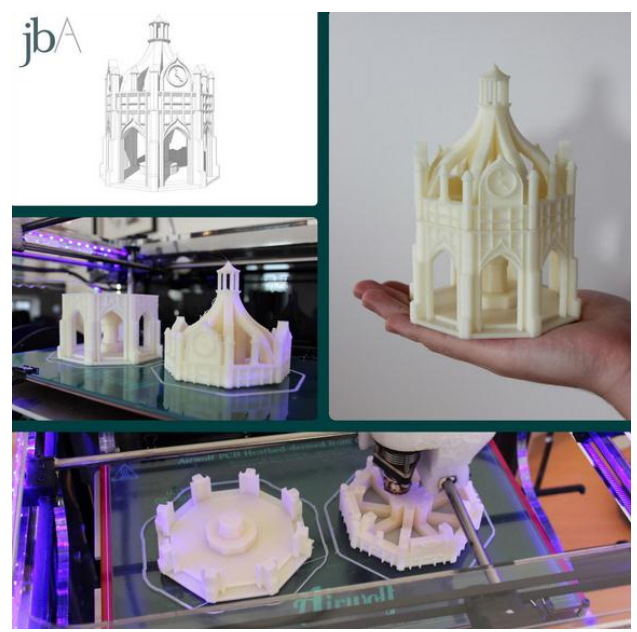

Figure 2. The Demonstration of the 3D Printing Technique

The Civil Modeling. Civil engineering informatization refers to the use of information processing technology such as the computer, communication, automatic control technology to the traditional civil engineering and construction methods, to modify and improve to promote the civil engineering technology and construction means perfect, make it more scientific and reasonable. By implementing civil online and sharing of information, provide the civil information support in the primary form of the interactive anytime and anywhere and complete solutions to problems, so as to realize the high efficiency and high efficiency of civil engineering.

Structural health monitoring in structure engineering is still in its infancy, the vast majority of the studies to test phase. The researchers at home and abroad in sensor technology, damage detection, pattern recognition, a lot of work on data processing, etc. a series of achievements. But few of these research results in the practical application results. At present, both at home and abroad applied in the actual bridge health monitoring system mostly belong to a single monitoring system, the monitoring system in the lack of comprehensive assessment mechanism to reflect the state of the bridge structure. In addition, in some of the existing bridge management system, the structural condition assessment method of subjectivity, to a large extent depends on the testing personnel's professional quality, hard to 
objective evaluation on the working state of the structure [7].

The Computer Civil Engineering. In computer plays a huge role in the construction of the civil engineering, improve the management level of civil engineering, using computer technology to civil engineering surveying data more accurate, provide data support for civil engineering construction. But in practice, the application of computer in civil engineering still lack a certain impetus, so should actively develop new technology research, strengthen the information management level of civil engineering, make the development of computer technology in civil engineering in the long term, for the civil engineering in information management and infrastructure to provide technical support.

Civil engineering informatization is to use the computer, communications, automatic control and dealing with information collection, high and new technology to the traditional civil engineering technology and construction methods, to modify and improve to promote the general civil engineering technology and construction means perfect, make it more scientific, reasonable, effectively improve the efficiency, reduce cost; Realize information will cause of civil engineering construction enterprise management mode of the profound revolution, is bound to promote the restructuring of the enterprise group and the construction process of optimization, make enterprise management ideas and means of innovation; Civil engineering informatization is the advanced stage of the market development, civil engineering will melt of modern logistics, e-commerce industry and information industry, so as to realize the high benefit, high efficiency of the civil engineering. Informatization construction of civil engineering must be committed to the construction of the three systems [8].

A wide range of application of computer in civil engineering in information management and the real-time monitoring of construction process and construction play a key role in such aspects as the quality control, face to the computer in the civil engineering concrete under content to do a detailed analysis. (1) In general construction of civil engineering, using computer to control the construction technology is one of the effective ways to improve the quality of construction as in the construction process of construction equipment to make use of the computer automatic control, for the effective control of construction technology management, efforts to realize the automation of the construction process. (2) In the implementation of project management control, the computer has played a big role. For real-time monitoring of the construction of civil engineering major is to pass information through the computer Internet sensors, monitoring of engineering construction process of the whole. (3) The computer provides information on the support for civil engineering construction, civil engineering construction to a certain extent, has been effectively guaranteed using the computer information management software, the computer program major of the civil engineering construction equipment, engineering design, engineering system, project quality, project budget, the cost of the project cost, project budget, project contract and construction personnel information management system.

The Civil Engineering Development Trend. Through the analysis of the above analysis should see the construction process and the traditional mechanical analysis has certain differences, there is the necessity of developing the definition of construction mechanics, also makes the construction process of the research into the development of a science of digital phase. Due to the differences in the process of construction, residual stress and residual deformation in the structure of the final state is different. Construction control technology should not only consider of configuration of mechanical equipment, labor, process arrangement, that should also consider finishing with minimum residual internal force and deformation of the structure. Therefore, the arrangement of the construction process should be comprehensive consideration of people, goods, content and the construction characteristics of the structure. 
Presented the construction mechanics not only solves the problems have long plagued the construction process, and will provide the basis for the future construction technology research, provide guarantee for ultimate control of the construction goal, the converted to active control of the passive control is used in different engineering fields [9].

Construction mechanics to some extent, can make the design from the perspective of construction design, also can make the construction personnel in terms of mechanical construction, and designed the structure of the internal force and deformation, the structural internal force and deformation of the actual finish as consistent as possible, make the applications of the materials and structure form is more reasonable and more secure. Application of computer in civil engineering has played a big role in engineering construction to promote the rapid development of engineering construction. Computer information chart make engineering drawing more intuitively reflected, and provided the basis for the engineering construction planning. The application of the relevant technology provides reliable data support for engineering reconnaissance, improve the level of the quality of the project as a whole. Computer technology should also be on the information management and the engineering software development to speed up the pace, provide more scientific computer application software for civil engineering, civil engineering construction to realize automation, improve the overall quality of civil engineering construction, make the cost optimization to improve the economic benefits of enterprises, promote the long-term development of the civil engineering construction.

\section{Conclusion}

In this paper, we conduct research on the computer and 3D modeling technology with applications on the modern civil engineering. Informatization strategy of civil engineering to civil engineering plays an important support to achieve the goal of the overall strategy. In this paper a few part of the civil engineering: structural engineering, geotechnical engineering basic traffic engineering, construction management, the environmental engineering, and summarizes the basic respective informationization development present situation, analyzes the existing problems, and puts forward the development trend. In the new era of rapid development of information technology, looking forward to the scholars of our country for more research and application achievements of civil engineering informatization for China civil engineering construction industry is the information tomorrow. In the later research, we will combine more literature reviews for optimization.

\section{References}

[1] Maurer, Brett W., et al. "Evaluating the Efficacy of Paleoliquefaction Analysis Techniques Using Modern Analogs." (2014).

[2] Bachmann, Christopher R., et al. "Accuracy Analysis of Close-Range Photogrammetry in Civil Engineering Projects." (2015).

[3] Jocovic, Mijat, et al. "Modern Business Strategy Customer Relationship Management in the Area of Civil Engineering." Applied Mechanics and Materials. Vol. 678. Trans Tech Publications, 2014.

[4] Lenczner, David. Elements of Loadbearing Brickwork: International Series of Monographs in Civil Engineering. Vol. 5. Elsevier, 2013.

[5] Zhong, W. A. N. G., C. H. E. N. Zhuo, and H. U. A. N. G. Xiang-gou. "On the Construction of the Teaching Team in Higher Vocational Colleges under the Modern Apprenticeship Teaching Model_-Taking the Construction of the Teaching Team in the Civil Engineering Major as an Example." Journal of Qingdao Technical College 2 (2013): 012. 
[6] Vlach, Tomáš, et al. "The Effect of Surface Treatments of Textile Reinforcement on Mechanical Parameters of HPC Facade Elements." Key Engineering Materials. Vol. 677. Trans Tech Publications, 2016.

[7] Klinc, R., I. Peruš, and M. Dolenc. "Re-using Engineering Tools: Engineering SaaS web application framework." Proceedings of the 2014 International Conference on Computing in Civil and Building Engineering. 2014.

[8] Liu, Yan Min. "Research on Civil Engineering with Ecological Impact
Assessment of Construction Activities." Advanced Materials Research. Vol. 859. 2014.

[9] Achillopoulou, Dimitra, and Athanasios Karabinis. "Proposed Model of Predicting the Reduced Yield Axial Load of Reinforced Concrete Columns Due to Casting Deficiency Effect." Transactions of the VŠB-Technical University of Ostrava, Civil Engineering Series. 14.2 (2014): 120-128. 